\title{
PROTECTIVE AND RISK FACTORS OF TODDLERS' SLEEP AND PARENTAL STRESS
}

\author{
Simona De Stasio \\ Department of Human Studies, LUMSA University, Rome, Italy \\ destasio.simona@gmail.com \\ Benedetta Ragni \\ Department of Human Studies, LUMSA University, Rome, Italy \\ Francesca Boldrini \\ Department of Human Studies, LUMSA University, Rome, Italy
}

Recepción Artículo: 14 Febrero 2020

Admisión Evaluación: 4 marzo 2020

Informe Evaluador 1: 18 marzo 2020

Informe Evaluador 2: 20 Marzo 2020

Aprobación Publicación: 20 abril 2020

\section{ABSTRACT}

The current study examined the network of relationships among toddlers' quality of sleep and emotion regulation, parental bedtime practices and involvement, parental self-perceived social support and stress, integrating a novel combination of psychosocial dimensions into a predictive model of quality of sleep and parental stress in a sample of 80 families with 2-3-year-old children. The results indicated that infants' emotion regulation, as well as proximal context variables, considering both maternal and paternal psychosocial functioning predicted variance in parental levels of stress. Furthermore, the findings showed that the number of child's night awakenings reported by mothers and the time requested by toddlers to fall asleep, were significantly related to parental distress levels as referred by both parents.

Keywords: sleep; toddlers; parental psychosocial functioning

\section{RESUMEN}

Factores protectors y de riesgo del sueño de los niños pequeños y del estrés de los padres. En el presente estudio se examinó la red de relaciones entre la calidad del sueño y la regulación de las emociones de los niños pequeños, las prácticas y la participación de los padres a la hora de acostarse, el apoyo social y el estrés de los padres, integrando una novedosa combinación de dimensiones psicosociales en un modelo predictivo de la calidad del sueño y el estrés de los padres en una muestra de 80 familias con niños de 2 a 3 años de edad. Los resultados indicaron que la regulación de las emociones de los lactantes, así como las variables de contexto próximo, teniendo en cuenta el funcionamiento psicosocial tanto materno como paterno, predecían la varianza de los niveles de estrés de los padres. Además, los resultados mostraron que el número de vigilancias nocturnas del niño comunicadas por las madres y el tiempo solicitado por los niños pequeños para dormirse, 


\section{PROTECTIVE AND RISK FACTORS OF TODDLERS' SLEEP AND PARENTAL STRESS}

estaban significativamente relacionados con los niveles de estrés de los padres según lo referido por ambos padres.

Palabras clave: sueño; niños pequeños; funcionamiento psicosocial de los padres

\section{INTRODUCTION}

The establishment of a well-regulated sleep-wake rhythm is a critical and complex developmental process in early infancy (Alfano et al., 2013; Bernier et al, 2013); although most infants consolidate their sleep habits during the first year of life, for many children, sleep is described as disrupted during toddlerhood (Tikotzky, Sadeh, \& Glickman-Gravieli, 2010). Commonly, toddlers present difficulties in initiating or maintaining sleep, and in returning to bed after night awakenings; furthermore, parents wishing to encourage healthy sleeping behaviors may find it challenging to define appropriate rules and limits (Johnson \& Mindell, 2011; Tikotzky, Sadeh, \& Glickman-Gravieli, 2010).

Along with individual child variables such as neurodevelopmental or temperamental characteristics, parenting behaviors appear to play a key part in determining children's normative sleep-wake patterns (Alfano et al., 2013). According to Alfano and coll., a wide range of parenting practices and parent-child interactions can either favor or interfere with children's sleep regulation (ibid.).

\section{Bedtimes routines in toddlerhood}

As documented in the literature, the establishment of routines during infancy has positive effects on children's patterns of biological regulation. According to Mindell et al. (2009), customary nightly routines induce significant improvement in toddlers' quality of sleep. "Bedtime routines" may be defined as habitual family patterns of behavior, whereby parents engage their child in recurring activities, in the same sequence every day before bed. Based on prior research, Tikotzky (2017) reported that, in preschoolers, stable routines are associated with shorter sleep latency, reduced night-awakening, less bedtime resistance, and longer night-time sleep duration, all markers of good quality sleep (Mindell, Telofski, Wiegand, Kurtz, 2009).

\section{Toddler emotion regulation}

Emotion regulation is the ability to decrease, maintain, or increase emotional arousal to facilitate engagement with the context (Molina et al., 2014). Existing literature show the critical role of caregiver behaviors and caregiver-child interaction, considering it the context in which children acquire their regulatory capacities (Feldman \& Eidelman, 2003). Children's regulation of affect responses and sleep patterns share a common developmental background, bidirectionally affecting one another (El Sheikh \& Sadeh, 2015). Emotional arousal and difficulty in regulating negative emotionality both influence sleep problems and stoke family processes whereby parents inadvertently maintain a sleep problem by acting to avoid child distress (Staples \& Bates, 2011).

\section{Parental Stress}

Recent research on the role of parental psychological well-being in young children's sleep quality has mainly focused on parental depression as a predictor of sleep disturbances (El-Sheikh \& Kelly, 2017).

Hughes et al. (2105) observed that mothers of 9-months old infants with less favorable sleep profiles reported depressive symptoms, poorer self-reported health, and significant levels of parenting stress. De Stasio and coll. (2018) found that mothers and fathers who reported significant levels of parental distress tended to describe their toddlers' bedtime routines as particularly challenging.

\section{Social Support}

It has been shown that parents' perceived social support is strongly associated with their personal capacity for adjustment (Cutrona \& Russell,1987) With respect to sleep, Morrell and Steele (2003) reported empirical evidence for an association between disrupted sleep-wake patterns in young children and parental psychosocial distress underpinned by perceptions of poor social support. 
Conversely higher levels of support can help parents to establish a positive family environment characterized by stability and cohesion, both of them conditions for regular sleep-wake patterns during infancy (Bernier et al., 2013).

\section{Maternal and paternal involvement during bedtime routines}

Previous studies have documented the role of both daytime and bedtime quality of parenting and parental strategies in predicting sleep disruptions in early childhood (Sadeh \& Anders, 1993; Morrell \& Cortina-Borja, 2002).

Responsive mothers fostered better quality and prolonged nighttime sleep in their infants (Jian \& Teti, 2016); by contrast, greater parental involvement, shorter response latency to infant awakenings and active soothing at bedtime negatively affect children's quality of sleep (ibid.).

While the role of mothers in children's sleep has been described in depth in the literature, the contribution of fathers has been little investigated to date (El-Sheikh \& Kelly, 2017).

Fathers who reported greater marital satisfaction and social support, and lower levels of parenting stress (Bernier, 2013), seem to be more involved in caring for their children at bedtime. Paternal involvement and provision of reliable emotional support to the child (Bernier et al., 2016) positively improve both children's and mothers' sleep consolidation (Tikotzky et al., 2015).

\section{Reciprocal influences}

From a transactional family dynamics perspective (Schermerhorn \& Cummings, 2008), children's developmental achievements, including sleep consolidation, are conceptualized as influencing and being influenced by multiple subsystems within the larger family system (Bernier et al., 2013). Research focusing on parenting and infants' sleep suggests the existence of reciprocal influences between them (Bell \& Belsky, 2008). Children's sleep problems undermine parents' sleep patterns and thereby their capacity to regulate emotion (Meltzer \& Mindell, 2007), essential to positive parenting (Bernier et al., 2013).

\section{The current study}

In the current study, we set out to advance understanding of the links between family factors and children's sleep by investigating the role of multiple dimensions of parental psychosocial functioning. We examined the network of relationships among toddlers' quality of sleep and emotion regulation, parental bedtime practices and involvement, parental self-perceived social support and stress, integrating a novel combination of psychosocial dimensions into a predictive model of quality of sleep and parental stress.

\section{METHOD}

\section{Participants and procedure}

80 Italian intact families of toddlers aging 18 to 36 months (48 M) were recruited. Criteria for participation were full-term pregnancy, absence of hospitalizations lasting more than a week and absence of any physical/mental disability. The mean age for parents in our sample was 34 years $(S D=4.1)$ for males and 36 years $(S D=4.2)$ for females. Parents had high levels of education $\left(M_{\text {males }}=18.2\right.$ years of education, $S D=1.8 ; M_{\text {females }}=17.6$, $\mathrm{SD}=2.4$ ), with only $3.1 \%$ of males and $1.8 \%$ of females reporting having completed high school or less. The $88 \%$ of the couples was married ( $M_{\text {marriage }}$ length= 7.3 years; $S D=2.6$ ), the $11 \%$ was engaged $\left(M_{\text {time together }}=7.1\right.$ years; $S D=5.3$ ). Participants received written information on Italian privacy regulations and signed informed consent. Measures were completed at home. The APA's ethical principles and code of conduct were observed (American Psychological Association, 2002). 


\section{PROTECTIVE AND RISK FACTORS OF TODDLERS' SLEEP AND PARENTAL STRESS}

\section{Instruments}

The Parent-Child Sleep Interaction Scale (PSIS; Alfano et al., 2013). The PSIS is a parent-report questionnaire which assess bedtimes behaviours and parent-child interactions related to problematic and dysfunctional sleep-wake patterns.

The Emotion Regulation Checklist (ERC; Shields \& Cicchetti, 1997, Molina et al.,2014). The ERC is a parent-report measure of children's self-regulation, composed by two subscale: the Lability/Negativity subscale (lack of flexibility and dysregulated negative affect) and the Emotion Regulation subscale (appropriate affective displays and emotional self-awareness).

The Parenting Stress Index (PSI-Short Form; Abidin, 1995). The PSI assesses parental perception of stress, perceiving in relation to child and parenting.

The Social Provisions Scale (SPS; Cutrona \& Russell, 1987). The SPS is a self-report questionnaire, assessing individuals' global perceptions of social support.

Parental involvement. By an ad-hoc questionnaire, perceptions of parents' involvement in bed-time children's caring was evaluated. The questionnaire was created on the basis of Parental Involvement Questionnaire (Tikotzky et al., 2015) given that - to the best of our knowledge - there were no existing Italian-language scales for measuring parental involvement. It was composed by 4 items rated on a 5-point Likert scale. The items assessed both night time involvement and overall (daytime) involvement. The composite score is computed by averaging all the items.

Sleep Quality Indicators. Sleep onset difficulties and nocturnal awakenings were evaluated with an ad-hoc questionnaire filled by mothers. They indicated how many times children wake during the night and how many minutes needed to settle down the child. Considering the Diagnostic Classification of Mental Health and Development Disorders of Infancy and Early Childhood (DC: 0-3R; Revised Edition; ZERO TO THREE, 2005) criteria to define Sleep Problems (Sleep Onset Disorder and Night Waking Disorder), we used sleep difficulties at bedtime (minutes take the child to fall asleep) and the number of night wakings as children's sleep quality indicators

\section{Data Analyses}

Bivariate correlations between the study variables were assessed by calculating the Pearson correlation coefficient. To gain further understanding of the relationships between the considered variables, multiple regressions were used. Three separate multiple regression analyses were conducted by regressing maternal and paternal parenting stress, infant's quality sleep in turn onto the correlated independent variables. The assumptions of linearity, normality, independence of observations, multicollinearity and homoscedasticity were assessed for each of the regression models and deemed to have been satisfactorily met.

\section{RESULTS}

Intercorrelations among the key variables are presented in Table 1. Correlations demonstrate suitably moderate associations among the variables to be included in the regression models, suggesting acceptable amounts of collinearity for the planned multivariate analyses.

\section{Multivariate Analyses}

Three separate multiple regression analyses were conducted to investigate the contributions of the relevant, correlated independent variables to variance in the dimensions of sleep quality. Linear multiple regression was performed in order to separately assess the contributions of each variable on maternal and paternal parental stress. In line with the literature reviewed, quality sleep variables, infant's emotion regulation dimensions and parental psychosocial functioning variables were entered. The results of the regression analyses are presented in Tables 2-4. The first linear regression $(F(9,49)=4.48 ; p>.05)$ revealed that the variables entered explained $50 \%$ of the variance in paternal parenting stress. In the model, paternal perceived social support was found to be the 
strongest predictor $(\beta=-.33, p=.008)$. The other predictors were the number of minutes required to settle down the children $(\beta=.26, p<.05)$ and paternal perception of child's emotional lability $(\beta=.29, p<.05)$.

As far as maternal parenting stress is concerned the regression model explains $57 \%$ of the variance in maternal parenting stress $\left(F_{(9,43)}=6.47, p<.001\right)$. In the model, maternal social support $(\beta=-.43, p<.001)$ and paternal global involvement in caring $(\beta=-.24, p=.051)$ negatively predicted maternal parenting stress, whereas maternal perception of child's emotional lability $(\beta=.37, p=.002)$ and number of nocturnal awakenings $(\beta=.30$, $p=.006$ ) were significant positive predictors of maternal parenting stress. Finally, linear regression was used to assess the independent variables' contribution to variance in number of night awakenings. The model explains $36 \%$ of the variance in the number of night awakenings reported by mothers. Maternal parenting stress was significant positive predictor $(\beta=.35, \mathrm{p}<.05)$ whereas paternal global involvement in caring negatively predicted $(\beta=-.33, p<.05)$ the number of night awakenings.

\section{DISCUSSION}

Main aim of the study was to explore the network of relationships among toddlers' quality of sleep and emotion regulation, parental bedtime practices and involvement, parental self-perceived social support and stress, integrating a combination of psychosocial dimensions into a predictive model of quality of sleep and parental stress. Considering transactional family dynamics framework (Schermerhorn \& Cummings, 2008), we found significant reciprocal associations between child sleep problems and familial dimensions. Our results suggest that maternal and paternal stress is linked to infants' quality of sleep: the number of night awakenings reported by mothers and the time required by toddlers to fall asleep were significantly associated with parental distress. These outcomes offer support to the assumption that toddlers' sleep can be influenced by interpersonal familial dynamics, as well as evidence for the potential agency of toddlers within the family system (Peltz et al., 2016). Sinai and Tikotzky (2012) suggested that parental perceptions of child's sleep behaviors may significantly impact parenting stress: parents considering their infant's sleep as challenging refer higher levels of stress. Furthermore, the results of regression analysis suggested that maternal and paternal stress is related to toddlers' emotional lability. The tendency to express negative emotionality at lower thresholds with greater intensity may induce infants to rely more strongly on caregivers, to obtain comfort (Troxel, 2013). Our results show that social support may act as protective factor of parental stress. Parents feeling supported by social context show greater emotional availability towards their infants, fostering children's emotion regulation abilities (Bernier et al., 2013). Researchers have typically focused little on paternal contributions to infant care (Bernier et al, 2016). According to existing literature, we found that paternal involvement in children's everyday care perceived by mothers, negatively predicted their own levels of parenting stress. A balance in caregiving responsibilities and a stable cooperation between parents can reduce maternal stress, positively influencing maternal and infant sleep (Tikotzky et al., 2015). Overall, we found that higher parental functioning is related to fewer night awakening. From our results maternal stress represents a risk factor for the increasing night awakenings, instead paternal involvement in children's bedtime care appear to act as protective factors for sleep quality (Dahl \& El-Sheikh, 2007). Our data confirm previous studies showing associations between higher levels of maternal stress and bedtime difficulties, less favorable child sleep profiles, and challenging bedtime routines (Hughes et al., 2015; De Stasio et al., 2018). Regarding parental involvement, several studies identified a relationship between paternal factors and children's sleep patterns (Bernier et al., 2016). Millikovsky et al (2015) found paternal involvement moderately influencing infant sleep, providing emotional and instrumental support for mothers and reducing their stress levels. The results of the current study shed light on the specific workings of reciprocity within the family system. Greater perceived social support and paternal involvement potentially enhance the parental dyad's capacity to jointly address any child sleep problems. 


\section{PROTECTIVE AND RISK FACTORS OF TODDLERS' SLEEP AND PARENTAL STRESS}

\section{TABLES}

Tab.1 Correlations among variables under study

\begin{tabular}{lcccccccccccc}
\hline Variable & $\mathbf{2}$ & $\mathbf{3}$ & $\mathbf{4}$ & $\mathbf{5}$ & $\mathbf{6}$ & $\mathbf{7}$ & $\mathbf{8}$ & $\mathbf{9}$ & $\mathbf{1 0}$ & $\mathbf{1 1}$ & $\mathbf{1 2}$ & $\mathbf{1 3}$ \\
\cline { 2 - 11 } 1. Children's & .23 & .11 & .05 & $.26^{*}$ & .04 & .05 & .00 & -.02 & $-.39^{* *}$ & $-.27^{*}$ & -.01 & -.08
\end{tabular}

Age

2. Min. settle down

3. N. Night

awakenings

4. Paternal

bedtime

involvement

(P)

$\begin{array}{llllllllllll}\text { 5. Paternal } & 1 & -.12 & .04 & -.13 & -.09 & .06 & -.07 & .00 & -.27^{*}\end{array}$

global

involvement

(P)

6. Paternal

problematic

bedtime

routines

7. Maternal

problematic

bedtime

routines

8. Paternal

$\begin{array}{lllllll}1 & .29 * & -.14 & .02 & -.04 & -.03\end{array}$

perceived

support

9. Maternal

perceived

support

10. Paternal

$.71 * *$

$\begin{array}{lll}-.05 & -.03 & .20\end{array}$

.12

$.38^{* *}$

$.36^{* *}$

parenting

stress

11. Maternal

$47 * *$

parenting

stress

12. Paternal

$1.62 * *$ emotional

lability

13. Maternal

emotional

lability 
Table 2. Regression coefficients of predictors of number of Paternal Parenting Stress

\begin{tabular}{|c|c|c|c|c|}
\hline \multirow[t]{2}{*}{ Variable } & \multicolumn{4}{|c|}{ Paternal Parenting Stress } \\
\hline & B & E.S. & $\boldsymbol{\beta}$ & $\mathbf{p}$ \\
\hline Min. settle down & .18 & .09 & .26 & .045 \\
\hline N. Night awakenings & 2.24 & 2.56 & .11 & .386 \\
\hline Paternal perception of child'emotional lability & 1.13 & .52 & .29 & .036 \\
\hline Paternal perceived support & -1.47 & .52 & -.33 & .008 \\
\hline Paternal problematic bedtime routines & .35 & .27 & .18 & .203 \\
\hline Paternal global involvement $(\mathrm{P})$ & 1.42 & 2.77 & .06 & .611 \\
\hline Paternal bedtime involvement $(\mathrm{P})$ & .84 & 2.38 & .05 & .726 \\
\hline Maternal global involvement $(\mathrm{P})$ & -2.23 & 3.37 & -.10 & .511 \\
\hline Maternal bedtime involvement $(\mathrm{P})$ & 3.99 & 2.65 & .23 & .14 \\
\hline .70 & & & & \\
\hline .50 & & & & \\
\hline
\end{tabular}

Table 3. Regression coefficients of predictors of number of Maternal Parenting Stress

\begin{tabular}{|c|c|c|c|c|}
\hline \multirow[t]{2}{*}{ Variable } & \multicolumn{4}{|c|}{ Maternal Parenting Stress } \\
\hline & B & E.S. & $\boldsymbol{\beta}$ & $\mathbf{p}$ \\
\hline Min. settle down & .09 & .91 & .11 & .318 \\
\hline N. Night awakenings & 6.09 & 2.12 & .30 & .006 \\
\hline Maternal perception of child'emotional lability & 1.49 & .46 & .37 & .002 \\
\hline Maternal perceived support & -2.09 & .50 & -.43 & .000 \\
\hline Maternal perception of probl bedtime routines & -.29 & .24 & -.14 & .221 \\
\hline Maternal global involvement (M) & -2.78 & 2.63 & -.12 & .296 \\
\hline Paternal global involvement (M) & $-4,66$ & 2.52 & -.24 & .051 \\
\hline Maternal bedtime involvement (M) & -.66 & 2.50 & -.03 & .791 \\
\hline Paternal bedtime involvement $(\mathrm{M})$ & -.55 & 2.01 & -.03 & .786 \\
\hline .75 & & & & \\
\hline .57 & & & & \\
\hline
\end{tabular}


Table 4. Regression coefficients of predictors of number of night awakenings

\begin{tabular}{|c|c|c|c|c|}
\hline \multirow[t]{2}{*}{ Variable } & \multicolumn{4}{|c|}{ N. Night awakenings } \\
\hline & B & E.S. & $\boldsymbol{\beta}$ & $\mathbf{p}$ \\
\hline Children's Age &,- 015 &, 023 &,- 094 &, 518 \\
\hline Min. settle down &,- 007 & ,006 &,- 188 & 249 \\
\hline Paternal emotional lability &, 010 &, 045 &, 048 & ,833 \\
\hline Maternal emotional lability &,- 039 &, 045 &,- 194 & ,394 \\
\hline Parental perceived support &,- 054 &, 036 &,- 237 & , 146 \\
\hline Paternal problematic bedtime routines &, 035 &, 023 &, 359 & , 144 \\
\hline Maternal problematic bedtime routines &,- 015 &, 023 &,- 150 &, 514 \\
\hline Paternal global parenting stress &,- 009 &, 012 &,- 184 & ,438 \\
\hline Maternal global parenting stress & 017 & ,009 & ,349 &, 050 \\
\hline Paternal bedtime involvement &,- 285 &, 138 &,- 333 &, 046 \\
\hline Maternal bedtime involvement &,- 065 &, 137 &,- 075 & ,638 \\
\hline .60 & & & & \\
\hline .36 & & & & \\
\hline
\end{tabular}

\section{BIBLIOGRAPHIC REFERENCES}

Abidin RR (1995). Parenting Stress Index. 3rd edition. Psychological, Odessa, FL.

Alfano, C. A., Smith, V. C., Reynolds, K. C., Reddy, R., \& Dougherty, L. R. (2013). The Parent-Child Sleep Interactions Scale (PSIS) for Preschoolers: Factor Structure and Initial Psychometric Properties. Journal of Clinical Sleep Medicine: JCSM : Official Publication of the American Academy of Sleep Medicine, 9(11), 1153-1160.

Bell B.G., Belsky J. (2008). Parents, parenting and children's sleep problems: Exploring reciprocal effects. British Journal of Developmental Psychology 26, 4, 579-593.

Bernier, A., Belanger, M.E., Bordeleau, S., \&Carrier, J. (2013). Mothers, fathers, and toddlers: Parental psychosocial functioning as a context for young children's sleep. Developmental Psychology, 49, 1375-1384.

Bernier, A., Tétreault, E., Bélanger, M., \& Carrier, J. (2016). Paternal involvement and child sleep: A look beyond infancy. Internationl Journal of Behavioral Development, 1-9.

Cutrona, C.E., \& Russell, D.W.,1987).The provisions of social relationships and adaptation to stress. Advances in personal relationships, 1(1), 37-67.

Dahl, R.E., El-Sheikh M. (2007): Considering sleep in a family context: introduction to the special issue. J Fam Psychol, 21, 1-3.

De Stasio, S., Ragni, B., Boldrini, F., Bevilacqua, F., Gentile, S. (2018). Parental stress and bedtime routines in toddlerhood. Anthropological Researches and Studies 8.

El-Sheikh M., Kelly R.J. (2017). Family Functioning and Children's Sleep. Child Dev Perspect, 11(4), 264-269.

El-Sheikh M., Sadeh A. (2015). I. Sleep and development: introduction to the monograph. Monogr Soc Res Child Dev. 80 (1), 1-14.

Feldman, R., Eidelman, A.I. (2003). Skin-to-skin contact (Kangaroo Care) accelerates autonomic and neurobehavioural maturation in preterm infants. Dev. Med. Child Neurol. 45, 274-281.

Goldberg W.A., Lucas-Thompson R.G., Germo G.R., Keller M.A., Poggi Davis E., Sandman C.A. (2013). Eye of the beholder? Maternal mental health and the quality of infant sleep. Social Science \& Medicine 79, 101-108. 
Hughes, A., Gallagher, S., Hannigan, A. (2015).: A cluster analysis of reported sleeping patterns of 9month old infants and the association with maternal health: results from a population Matern Child Health J., 19 (8), 1881-1889

Johnson, C., Mindell, J.A. (2011). Family based interventions for sleep problems of infants and children. In M. El-Sheikh (Ed.), Sleep and development: Familial and sociocultural considerations (373-395). New York, NY: Oxford University Press.

Meltzer L.J., Mindell J.A. (2007). Relationship between child sleep disturbances and maternal sleep, mood, and parenting stress: A pilot study. Journal of Family Psychology 21, 1, 67-73.

Millikovsky-Ayalon M, Atzaba-Poria N, Meiri G (2015). The role of the father in child sleep disturbance: child, parent, and parent-child relationship. Infant mental health journal 36 (1), 114-127.

Mindell, J.A., Telofski L.S., Wiegand B., Kurtz E.S., (2009). A nightly bedtime routine: impact on sleep in young children and maternal mood. Sleep, 32(5), pp.599-606.

Molina P., Sala M.N., Zappulla C., Bonfigliuoli C., Cavioni V., Zanetti M.A., et al. (2014). The Emotion Regulation Checklist - Italian translation. Validation of parent and teacher versions. The European Journal of Developmental Psychology 5 (11), 624-634.

Morrell, J., \& Steele, H. (2003), The role of attachment security, temperament, maternal perception, and care-giving behavior in persistent infant sleeping problems. In Infant Mental Health Journal, 24, 2003, pp. 447-468.

Peltz J.S., Rogge R.D., Sturge-Apple M.L., O'Connor T.G., Pigeon W.R. (2016).: Reciprocal influences among family processes and toddlers' sleep problems. J Fam Psychol, 30 2016, 30:, 720-731.

Sadeh, A., Flint-Ofir, E., Tirosh, T., \& Tikotzky, L. (2007). Infant sleep and parental sleep-related cognitions. Journal of Family Psychology, 21, 74-87.

Sadeh, A., Tikotzky, L., \& Scher, A. (2010). Parenting and infant sleep. Sleep Medicine Reviews, 14(2), 89-96.

Schermerhorn A.C., Cummings E.M., (2008). Transactional Family Dynamics: A New Framework for Conceptualizing Family Influence Processes. Advances in Child Development and Behavior, 36, 187-250.

Shields A, Cicchetti D (1997). Emotion regulation among school age children: The development and validation of a new criterion q-sort scale. Developmental Psychology 33, 6, 906-916.

Sinai D, Tikotzky $L$ (2012). Infant sleep, parental sleep and parenting stress in families of mothers on maternity leave and in families of working mothers. Infant Behavior and Development 35, 2, 179-186.

Staples, A. D., \& Bates, J. E. (2011). Children's sleep and cognitive and behavioral adjustment. In M. El-Sheik (Ed.). Familial and Socio-cultural Influences on Children's Sleep (133-163). NY: Oxford University Press.

Teti, D.M., Shimizu M., Crosby B., Kim B.R. (2016): Sleep arrangements, parent-infant sleep during the first year, and family functioning. Dev Psychol, 52, 1169-1181.

Tikotzky, L., Sadeh A., Glickman-Gavrieli T. (2010). Infant sleep and paternal involvement in infant caregiving during the first 6 months of life. Journal of Pediatric Psychology 36(1), 36-46.

Tikotzky, L., Sadeh A., Volkovich E., Manber R., Meiri G., Shahar G. (2015). Infant sleep development from 3 to 6 months postpartum: links with maternal sleep and paternal involvement. Monographs Society Res Child $80,107-124$.

Zero to Three. (2005). Diagnostic classification: 0-3R: Diagnostic classification of mental health and developmental disorders of infancy and early childhood: revised edition (revised edn). Washington, DC: Zero To Three Press 
